\title{
A Formação Continuada e seus Reflexos no Encaminhamento da Produção Textual
}

\author{
The Continuous Formation and your Reflections in the TeXtual \\ Production Routing
}

Rosemary de Oliveira Schoffen Turkiewicz*
Terezinha da Conceição Costa-Hübes**

Resumo: Este artigo tem o intuito de analisar e compreender alguns resultados apresentados em decorrência da participação do professor da educação básica em uma atividade de formação continuada realizada em Goioerê-PR, que teve como propósito provocar reflexões sobre o ensino da produção escrita na escola, abrangendo o encaminhamento da produção textual, a revisão e a reescrita de textos de alunos da educação básica. Tal formação constituiu-se como um dos instrumentos de geração de dados da pesquisa "Ações Colaborativas para encaminhamentos da produção e da reescrita textual no ensino fundamental" que está em andamento. Por constituir uma pesquisa colaborativa, pretende auxiliar a prática docente, de modo a torná-la mais consistente e consoante com os pressupostos teóricos e metodológicos que regem os atuais referenciais curriculares de Língua Portuguesa. Dados os limites deste texto, nos propomos a analisar os reflexos da formação apenas quanto à primeira parte do processo: os encaminhamentos feitos pelo professor para a produção escrita de seus alunos e como essa proposta se consolidou nos textos produzidos pelas crianças. Para proceder a este estudo, nos pautamos nos pressupostos do círculo bakhtiniano; na proposta de

\footnotetext{
* Mestranda no Programa de Pós-Graduação em Letras, da Universidade Estadual do Oeste do Paraná - UNIOESTE. Professora da rede estadual de ensino do Paraná. Contato: rost.pr@gmail.com.

** Doutora em Estudos da Linguagem pela Universidade Estadual de Londrina (2008). Professora Doutora Adjunto D - UNIOESTE. Contato: tehubes@gmail.com.
} 
Geraldi (2006), nos estudos de Magalhães (2004), Costa-Hübes (2012), entre outros.

Palavras-chave: Formação de professores. Produção textual. Ensino da Língua Portuguesa.

Abstract: This article intents to analyze and understand some results presented due to elementary school teachers participation in a continuous education activity held in Goioerê-PR, which had a goal to provoke a reflection about how to teach essay production at school, how to revise it and rewrite essays produced by elementary school students. Such training is established as an instrument to create research data to "Colaborative Actions to development of production and essay rewriting at elementary school study" that is in progress. Because this is a collaborative research its main goal is to assist the teaching practice in order to make it more consistent and unique with the theoretic and methodologic principles that are ruling our current curricular Portuguese language grade nowadays. Given the limits of this paper, we proposed to analyze the effects of the training as far as the first part of this process: the references given by the teachers to the students to produce the essay and how this proposal was consolidated in the texts produced by the children. To proceed with such study, we are holding on Bakhtin Circle assumptions; Geraldi's proposals (2006), Magellan studies (2004), Costa-Hübes (2012), and others.

Keywords: Teacher training. Textual production. Portuguese Language teaching.

\section{Introdução}

O que temos observado, na área de Língua Portuguesa (LP), é que nas últimas décadas, mais especificamente a partir dos anos de 1980, muito se tem discutido no país sobre seu ensino na educação básica. Historicamente, foi mais precisamente na década de 1980 que as discussões foram aquecidas pelas ideias do Círculo de Bakhtin, período em que suas obras começavam a ser traduzidas e divulgadas no Brasil, inserindo-se nos meios acadêmicos. 
Com os estudos bakhtinianos, introduziu-se uma definição histórico-discursiva do sujeito, o reconhecimento da linguagem como dialógica e a serviço da interação (BAKHTIN/VOLOCHINOV, 2014). Educadores e estudiosos direcionaram, então, essa teoria para o ensino e definiu-se uma abordagem interacionista de trabalho com a linguagem. Dentre tais estudiosos, destacamos Geraldi (2006), um dos primeiros autores brasileiros a inserir as ideias bakhtinianas em seus estudos, apontando-as como fundamentos para as práticas pedagógicas nas aulas de LP. Inicialmente, o autor aplicou os conceitos propostos por Bakhtin ao trabalho com o texto, que passou a ser reconhecido como unidade de ensino, em uma proposta de trabalho com a língua (oral e escrita) sustentada na concepção de linguagem como forma de interação.

No estado do Paraná, tais pressupostos têm permeado as discussões curriculares e a elaboração de documentos referenciais desde a década de 1990, pois essas reflexões já se delineavam na construção do Currículo Básico para a Escola Pública do estado do Paraná (CBPR) (PARANÁ, 1990), documento que impulsionou uma mudança metodológica ao reconhecer o texto como princípio norteador para as aulas de LP. Alguns anos depois, com a publicação dos Parâmetros Curriculares Nacionais (PCN) (BRASIL, 1997, 1998), a concepção interacionista da linguagem foi divulgada amplamente, estendendo a compreensão do trabalho com a língua a partir do texto, para os gêneros do discurso/textuais ${ }^{1}$. A partir da publicação desse documento, os pressupostos bakhtinianos começaram a ser discutidos amplamente nas universidades, o que gerou novas pesquisas e provocou um maior amadurecimento teórico.

Em 2003, a Secretaria de Estado da Educação do Paraná (SEED/PR), após realizar um diagnóstico acerca das propostas curriculares em vigor nos estabelecimentos de ensino estaduais e defrontar-se com um hibridismo de concepções nos documentos, propôs estudos envolvendo os professores da rede estadual de ensino, tanto da Educação Básica quanto do

${ }^{1}$ Embora a teoria bakhtiniana apareça implícita nas discussões do documento, o que se destaca efetivamente é a compreensão de gênero textual, com base nas reflexões de autores genebrinos como Bronckart (1999). Por isso, os gêneros ora são tratados como "discursivos" (BAKHTIN, 2003), ora como textuais (BRONCKART, 1999). 
Ensino Superior, com o intuito de subsidiar a elaboração de um novo referencial curricular para o estado que melhor atendesse a prática pedagógica em consonância com o amadurecimento das discussões teóricas. Como resultado, produziu e publicou as Diretrizes Curriculares Estaduais (DCE), em 2008 (PARANÁ, 2008), documento que assumiu a concepção dialógica e interacionista da linguagem como princípio teórico norteador, a partir dos pressupostos bakhtinianos.

Todavia, mesmo décadas após as primeiras discussões quanto à concepção de linguagem explicitada nos documentos (CBPR, PCN e DCE), ainda nos deparamos, muitas vezes, com o ensino da produção textual centrado em uma orientação formal-sistêmica, que privilegia o exercício da escrita, em detrimento da produção escrita para a interação. Se o texto é reconhecido, nos documentos (especificamente nos PCN e DCE) como unidade de ensino que se configura em determinado gênero discursivo, as propostas de produção de texto na escola deveriam priorizar a interação, haja vista que, para Bakhtin/Volochinov (2014), a língua só se realiza em enunciados concretos dentro de um processo de interação. O distanciamento dessa compreensão, na escola, nos leva a crer que tais pressupostos não foram compreendidos pelos professores da educação básica, talvez pelo fato de não ter ocorrido uma formação adequada e/ou período de tempo suficiente para articular teoria e prática, conforme o que rege os documentos.

Diante desse contexto e do propósito de entender as dificuldades para encaminhamento da produção textual na escola é que nos debruçamos sobre os seguintes questionamentos:

- Como são feitos os encaminhamentos da produção e reescrita de textos em turmas do ensino fundamental, de modo a contemplar as orientações teórico-metodológicas que constam nos documentos curriculares?

- De que modo a formação continuada pode colaborar para aprofundar conhecimentos e, consequentemente, refletir nos encaminhamentos da produção e reescrita de texto na escola?

$\mathrm{Na}$ perspectiva de responder aos questionamentos, tal pesquisa circunscreve-se no âmbito da Linguística Aplicada (LA), uma vez que analisamos a linguagem em uso. Trata-se de uma pesquisa qualitativa, de tipo etnográfico, constituindo-se como pesquisa-ação-crítico-colaborativa, pois, por meio de ações de formação continuada (FC), pretendemos colaborar 
com os docentes, sujeitos da pesquisa, de modo que possam, assim como diz Pimenta (2005, p. 523), "problematizar suas ações", considerando a reflexão crítica e conjunta entre sujeitos participantes e pesquisadora.

Em pesquisas colaborativas, o principal enfoque é aproximar os estudos acadêmicos das práticas sociais, em nosso caso, das práticas pedagógicas que se efetivam em sala de aula, no intuito de redimensionar as ações do pesquisador e do professor da educação básica. Assim, os sujeitos da pesquisa são professores de LP do ensino fundamental de duas escolas públicas do município de Goioerê-PR. Para geração de dados, recorremos à entrevista, à observação participante em sala de aula e a dados gerados a partir da FC.

Nesse sentido, após observarmos aulas em turmas do $6^{\circ}$ ano e levantarmos as maiores dificuldades dos professores com o encaminhamento da produção e da reescrita textual, propusemos, como uma das etapas fundamentais de nossa pesquisa, uma formação de professores. Nela, assumimos a concepção dialógica e discursiva de linguagem e de ensino de língua, fundamentada nas ideias bakhtinianas e no que propagam os documentos curriculares (PCN e DCE).

Diante do exposto, o objetivo deste texto, que apresenta apenas um recorte da pesquisa em andamento ${ }^{2}$, é analisar alguns desdobramentos e resultados observados durante o processo de formação, ao olhar para uma proposta de produção textual e sua efetivação na produção escrita de alunos.

Para atingir tal objetivo, apresentamos, na primeira parte do texto, uma descrição do como se originou a proposta de FC, discutindo sobre seu papel como etapa integrante da pesquisa em andamento. Depois, discorremos sobre a base teórica que fundamenta todo o trabalho desenvolvido, refletindo sobre sua articulação com o que está previsto nos atuais documentos curriculares do estado do Paraná, as DCE (PARANÁ, 2008). Por fim, analisamos um encaminhamento (comando) de produção textual, elaborado e aplicado após os primeiros encontros de FC, bem como os textos

2 Trata-se de uma pesquisa de mestrado ligada ao Programa de Pós-Graduação em Letras da Universidade Estadual do Oeste do Paraná, que se iniciou em março de 2014 e tem seu término previsto para setembro de 2016. 
produzidos pelos alunos, procurando observar como os conceitos teóricos abordados se fizeram presentes na ação do professor.

\section{A Proposta de Formação Continuada como uma Etapa de Pesquisa}

Consideramos que refletir sobre a FC, sobre sua importância na condução das práticas pedagógicas, no sentido de articular teoria e prática, constitui um grande desafio, pois requer que a compreendamos como uma extensão da sala de aula, momento que o professor teria para rever conceitos, relacioná-los com encaminhamentos didáticos, aprofundando, assim, seus conhecimentos. Todavia, parece-nos que não é essa a compreensão das políticas que regem o ensino, pois, ao longo dos anos, pouco se tem ofertado em termos de FC. As formações ocorrem tanto na rede de ensino estadual quanto na municipal, mas de forma estanque, pontual, quando o professor ouve ou recebe uma grande quantidade de informações em reduzido espaço de tempo, sem possibilidade para uma ampla reflexão que favoreça confrontar os conceitos teóricos com a prática pedagógica.

De acordo com Gedoz e Costa-Hübes (2013, p. 231), “a política de formação continuada para professores, geralmente, é caracterizada como fragmentada, descontínua e utilitarista, voltada especificamente a interesses educacionais ditados pelas políticas que surgem a cada mandato político no cenário nacional". Essa fragmentação do processo gera dificuldade em atingir seu principal objetivo que seria subsidiar os professores quanto à atuação em sala de aula.

Diante desse contexto, optamos por inserir uma proposta de FC como uma das etapas centrais de nosso projeto, a qual está fundamentada nos princípios da pesquisa colaborativa e reflexiva, tal como orientam diversos estudiosos como Cristovão (2004), Magalhães (2004), Pimenta (2005) e Coelho (2011).

Para o planejamento dessa proposta, tomamos como indicativo o que nos foi apontado nas entrevistas e nas observações de vinte aulas de LP que acompanhamos no período de outubro/novembro de 2014, ministradas nos $6^{\circ}$ anos do ensino fundamental em dois estabelecimentos de ensino da rede estadual do município de Goioerê-PR. 
Após a análise dos dados gerados por esses instrumentos de pesquisa (entrevista e observação participante) e diálogo com as docentes que seriam nossas colaboradoras, consideramos de suma importância a organização de uma proposta de FC que fosse estendida também aos professores de $5^{\circ}$ ano, por entendermos que a articulação entre as duas etapas do ensino fundamental poderia contribuir para o processo de ensino e aprendizagem da escrita na educação básica.

Para isso, elaboramos um projeto de FC, intitulado "Produção escrita na escola: desafios do ensino e da aprendizagem", envolvendo professores de $5^{\circ}$ a $9^{\circ}$ anos. Essa ação de formação se efetivou em 58 horas, com parte da carga horária destinada a encontros presenciais e estudos teóricos e outra parte para elaboração e aplicação de atividades que seriam relatadas e analisadas à luz dos conceitos estudados. Procuramos, assim, desenvolver com os participantes um trabalho de caráter colaborativo e reflexivo, de modo a provocar observações que estabelecessem relação entre a teoria e a prática, pois, segundo Magalhães (2004, p. 70),

É fundamental que as interações em contextos de formação não enfoquem apenas o conteúdo a ser transmitido sem qualquer reflexão sobre a audiência a que se destina e os interesses que as embasam, mas que propiciem aos participantes um distanciamento e um estranhamento de práticas rotineiras e raramente questionadas, para que reflexão e crítica tenham lugar.

A formação teve início no mês de abril de 2015, estendendo-se até o final de junho de 2015, sendo organizada de forma a articular, a todo o momento, a relação indissociável entre a teoria e a prática de sala de aula, sem perder o foco de nossa pesquisa: o processo de produção textual encaminhamento da proposta - revisão e reescrita textual, seguindo os pressupostos que regem o ensino, tal como asseguram as DCE (PARANÁ, 2008).

Tal procedimento metodológico teve o intuito de proporcionar momentos em que o professor "olhasse" para sua prática e confrontasse o que está discutindo teoricamente com o que está fazendo, para que pudesse analisar por que faz o que faz e da forma que faz. Assim, concordamos com 
o que assevera Magalhães (2004, p. 78): “é a compreensão do que realmente faz e de seus significados que leva o professor ao entendimento dos interesses que embasam as ações diárias da sala de aula, isto é, das significações que estão sendo negociadas e/ou transmitidas".

O grupo consolidou-se com 21 docentes, sendo que 11 atuavam na rede estadual de ensino, com turmas de $6^{\circ}$ a $9^{\circ}$ anos; os outros 10 pertenciam ao quadro da rede municipal, todos docentes em turmas de $5^{\circ}$ ano da educação básica.

Os encontros seguiram a ordem de estudos sistematiza no Quadro 1, a seguir:

Quadro 1 - Planejamento das ações de Formação Continuada

\begin{tabular}{|c|c|c|}
\hline Datas & Conteúdo & $\begin{array}{c}\text { Carga } \\
\text { horária }\end{array}$ \\
\hline $\begin{array}{c}30 / 04 / 2015 \\
a \\
03 / 05 / 2015\end{array}$ & $\begin{array}{l}\text { Estudo do texto: BARREIROS, Ruth Ceccon; } \\
\text { COSTA-HÜBES, Terezinha da Conceição. } \\
\text { Concepções e capacidades de Leitura para o } \\
\text { letramento. In: COSTA-HÜBES, Terezinha da } \\
\text { Conceição et al. Descritores da Prova Brasil ( } 5^{\circ} \text { ano): } \\
\text { estudos e proposições didáticas. São Carlos: Pedro \& } \\
\text { João, 2014. p. 19-42. }\end{array}$ & $2 \mathrm{~h}$ \\
\hline $\begin{array}{l}04 / 05 / 2015 \\
\text { Sessões } \\
\text { reflexivas/ } \\
\text { interativas }\end{array}$ & $\begin{array}{l}\text { Oficina sobre atividades de leitura numa perspectiva } \\
\text { discursiva de linguagem; } \\
\text { Discussão sobre a influência da leitura para o processo } \\
\text { de escrita de textos; } \\
\text { Texto de apoio: Concepção de leitura e sua influência na } \\
\text { elaboração de questões - Síntese elaborada pela Profa. Dra. } \\
\text { Terezinha da Conceição Costa-Hübes - jun./2014. }\end{array}$ & $4 \mathrm{~h}$ \\
\hline $\begin{array}{l}05 / 05 / 2015 \\
a \\
10 / 05 / 2015\end{array}$ & $\begin{array}{l}\text { Análise das questões que estão sendo aplicadas em sala } \\
\text { de aula, seja do livro didático ou outros materiais, } \\
\text { observando se exploram mais a decodificação, } \\
\text { inferenciação ou análise linguística. }\end{array}$ & $4 \mathrm{~h}$ \\
\hline $\begin{array}{l}11 / 05 / 2015 \\
\text { Sessões } \\
\text { reflexivas/ } \\
\text { interativas }\end{array}$ & $\begin{array}{l}\text { Apresentação e discussão sobre as análises. Exercício } \\
\text { de elaboração de atividades de leitura a partir de textos } \\
\text { selecionados previamente numa perspectiva discursiva } \\
\text { de linguagem. }\end{array}$ & $4 \mathrm{~h}$ \\
\hline
\end{tabular}




\begin{tabular}{|c|c|c|}
\hline $\begin{array}{c}12 / 05 / 2015 \\
a \\
17 / 05 / 2015\end{array}$ & $\begin{array}{l}\text { Estudo do texto: COSTA-HÜBES, Terezinha da } \\
\text { Conceição. Reflexões sobre os encaminhamentos de } \\
\text { produção textual: enunciados em diálogo com outros } \\
\text { enunciados. In: Anais do X Encontro do CELSUL - } \\
\text { Círculo de Estudos Linguísticos do Sul UNIOESTE - } \\
\text { Universidade Estadual do Oeste do Paraná. Cascavel- } \\
\text { PR, 2012. }\end{array}$ & $4 \mathrm{~h}$ \\
\hline $\begin{array}{l}18 / 05 / 2015 \\
\text { Sessões } \\
\text { reflexivas/ } \\
\text { interativas }\end{array}$ & $\begin{array}{l}\text { Estudos e reflexões sobre gêneros discursivos e } \\
\text { produção escrita à luz do texto estudado. }\end{array}$ & $4 \mathrm{~h}$ \\
\hline $\begin{array}{c}19 / 05 / 2015 \\
a \\
24 / 05 / 2015\end{array}$ & $\begin{array}{l}\text { Leitura do texto: COSTA-HÜBES Terezinha da } \\
\text { Conceição. Análise de textos de alunos dos anos } \\
\text { iniciais: orientações para um possível diagnóstico. } \\
\text { Work. pap. 12:14 13(3): 01-20, Florianópolis, out./dez. } \\
2012 \text {. } \\
\text { Coleta de amostra de comando de produção escrita e } \\
\text { textos produzidos pelos alunos. }\end{array}$ & $6 \mathrm{~h}$ \\
\hline $\begin{array}{c}25 / 05 / 2015 \\
\text { e } \\
01 / 06 / 2015 \\
\end{array}$ & $\begin{array}{l}\text { Estudos e reflexões sobre os comandos de produção e } \\
\text { análise diagnóstica de textos escritos produzidos pelos } \\
\text { alunos. }\end{array}$ & $8 \mathrm{~h}$ \\
\hline $\begin{array}{c}02 / 06 / 2015 \\
a \\
07 / 06 / 2015\end{array}$ & $\begin{array}{l}\text { Leitura do texto: } \\
\text { GASPAROTTO, Denise Moreira; MENEGASSI, } \\
\text { Renilson José. Modos de participação do professor na } \\
\text { reescrita de alunos: enfoque na análise linguística. In: } \\
\text { Anais do X Encontro do CELSUL - Círculo de Estudos } \\
\text { Linguísticos do Sul UNIOESTE - Universidade } \\
\text { Estadual do Oeste do Paraná. Cascavel-PR, 2012. } \\
\text { Análise diagnóstica de textos de alunos. }\end{array}$ & $6 \mathrm{~h}$ \\
\hline $\begin{array}{l}08 / 06 / 2015 \\
\text { Sessões } \\
\text { reflexivas/ } \\
\text { interativas } \\
\end{array}$ & $\begin{array}{l}\text { Estudos e reflexões sobre a reescrita de texto na sala } \\
\text { de aula. }\end{array}$ & $4 \mathrm{~h}$ \\
\hline $\begin{array}{l}15 / 06 / 2015 \\
\text { Sessões } \\
\text { reflexivas/ } \\
\text { interativas }\end{array}$ & $\begin{array}{l}\text { Estudos e reflexões sobre a reescrita de texto na sala } \\
\text { de aula. }\end{array}$ & $4 \mathrm{~h}$ \\
\hline $\begin{array}{l}22 / 06 / 2015 \\
\text { Sessões } \\
\text { reflexivas/ } \\
\text { interativas }\end{array}$ & Produção de atividades de reescrita de texto. & $4 \mathrm{~h}$ \\
\hline
\end{tabular}




\begin{tabular}{|c|c|c|}
\hline $\begin{array}{c}29 / 06 / 2015 \\
\text { Sessões } \\
\text { reflexivas/ } \\
\text { interativas }\end{array}$ & Produção de atividades de reescrita de texto. & $4 \mathrm{~h}$ \\
\hline \multicolumn{2}{|c|}{ Total } & 58 horas \\
\hline
\end{tabular}

A FC organizou-se da seguinte forma: os participantes liam, antecipadamente, os textos motivadores das reflexões; depois, esses textos eram debatidos/explorados coletivamente, com a nossa mediação e, posteriormente, eram produzidos relatos reflexivos sobre os textos lidos/ debatidos, procurando relacionar a leitura com encaminhamentos didáticos. Além disso, os professores produziam atividades procurando contemplar aquela orientação teórica.

Destacamos que todos os relatos reflexivos, bem como as atividades elaboradas, constituem registros do trabalho e, portanto, foram tomados como corpus de análise para nossa pesquisa. Dentre esse corpus, selecionamos, para este texto especificamente, um relato de prática com a produção escrita, no qual consta todo um processo de encaminhamento de produção textual envolvendo alunos do $5^{\circ}$ ano. Além disso, selecionamos também textos produzidos pelos alunos, resultados desse encaminhamento, os quais nos foram disponibilizados pela professora. Nosso propósito, portanto, é refletir, a partir desse material, sobre os possíveis reflexos da FC no cotidiano escolar, analisando se, de fato, os cursos de formação produzem efeito na prática pedagógica de professores.

\section{Fundamentos Teóricos da Pesquisa e da Formação Continuada}

Durante o processo de FC desenvolvido em uma fase da pesquisa, nos pautamos na concepção interacionista e dialógica da linguagem que encontra sustentação nos pressupostos bakhtinianos, haja vista ser este o referencial teórico que embasa a proposta de ensino de LP nas DCE (PARANÁ, 2008). Assumir essa postura significa reconhecer que a linguagem se concretiza em contextos sociais e históricos, os quais a influenciam e, ao mesmo tempo, são por ela influenciados, negando a concepção de linguagem como algo estático, apenas sistema. 
Portanto, para o trabalho com a produção de texto na escola, o primeiro ponto a se considerar é a natureza dialógica da linguagem, o que requer que essa prática seja reconhecida como atividade de interação. Para os pensadores do Círculo, o dialogismo constitui um princípio norteador que sustenta os demais conceitos bakhtinianos. Bakhtin (2010, p. 209) defende que

As relações dialógicas são extralinguísticas. Ao mesmo tempo, porém, não podem ser separadas do campo do discurso, ou seja, da língua como fenômeno integral concreto. A linguagem só vive na comunicação dialógica daqueles que a usam. [...] Toda vida da linguagem, qualquer que seja seu campo de emprego, está impregnada de relações dialógicas.

Desse modo, é preciso que, como educadores, tenhamos bem definido que, ao assumirmos os postulados do círculo de Bakhtin, reconhecendo a linguagem em uma concepção dialógica e interacionista, não será mais possível abordar a língua apenas por meio de estudos linguísticos descontextualizados, de uma forma sistêmica formal, apenas como objeto, uma vez que, para Bakhtin (2010, p. 208), "Na linguagem, como objeto da linguística, não há nem pode haver quaisquer relações dialógicas: estas são impossíveis entre os elementos no sistema da língua".

Para Bakhtin/Volochinov (2014), a linguagem, em sua expressão oral ou escrita, consolida-se na interação e se constitui na ação social entre interlocutores. Concebida como interação, a linguagem é viva, materializada em textos-enunciados. Para Bakhtin (2015, p. 300), "O enunciado é um elo na cadeia da comunicação discursiva e não pode ser separado dos elos precedentes que o determinam tanto de fora quanto de dentro, gerando nele atitudes responsivas diretas e ressonâncias dialógicas".

$\mathrm{O}$ enunciado, assim, remete ao uso da linguagem, pois concretiza o projeto de dizer nos diversos campos da atividade humana, conforme as necessidades de interação e dos modos de compreensão da realidade. "Nesse sentido, ensinar o aluno a produzir textos, significa conduzir encaminhamentos que orientem para a produção concreta de enunciados, organizados por meio de um gênero discursivo" (COSTA-HÜBES, 2012, p. 9). 
Os gêneros discursivos organizam os enunciados que se efetivam na sociedade e se constituem a partir do conteúdo temático, do estilo e da construção composicional que, para Bakhtin (2015), estão intrinsicamente ligados no todo do enunciado. O nosso "dizer" toma forma em enunciados que se moldam em um gênero do discurso produzido por uma determinada esfera de atividade humana. Tudo que falamos ou escrevemos está ligado a uma esfera social. Para Bakhtin (2015, p. 262), os gêneros dão forma aos enunciados concretos produzidos na "multiforme atividade humana [...] o repertório dos gêneros do discurso cresce e se diferencia à medida que se desenvolve e se complexifica um determinado campo".

Faraco (2013, p. 127) destaca esse aspecto ao afirmar que "o repertório de gêneros de cada esfera da atividade humana vai diferenciando-se e ampliando-se à medida que a própria esfera se desenvolve e fica mais complexa". Ainda, segundo o autor, as ideias do Círculo demonstram uma

... estreita correlação entre os tipos de enunciados (gêneros) e suas funções na interação socioverbal [...] nossos enunciados têm conteúdo temático, organização composicional e estilo próprios correlacionados às condições específicas e às finalidades de cada esfera de atividade. (FARACO, 2013, p. 126).

Tomando essa compreensão como referência, as DCE (PARANÁ, 2008) definem como conteúdo estruturante o discurso como prática social, orientando que a língua deve ser trabalhada em sala de aula a partir da linguagem em uso, considerando os gêneros discursivos que circulam socialmente como conteúdos básicos. Preconiza que, "na abordagem de cada gênero é preciso considerar o tema (conteúdos ideológicos), a forma composicional e o estilo (marcas lingüísticas e enunciativas)" (PARANÁ, 2008, p. 64).

Diante do exposto, é inegável a importância de se trabalhar nas escolas com uma perspectiva de uso social da linguagem, recorrendo aos textos que circulam socialmente para ensinar a leitura e a escrita. Tais questões estão contempladas em nossos estudos e foram abordadas durante a FC, uma vez que o trabalho que considera a língua como interação deve assumir, na produção textual, uma necessidade de dizer algo para alguém, o que 
pressupõe sempre um interlocutor. Esse caráter social da língua deve ser um eixo motivador para a produção (oral ou escrita) do aluno que não terá apenas no professor o seu interlocutor.

Geraldi (2006), em suas primeiras discussões sobre o trabalho com texto em sala de aula, já destacava a necessidade de rever o trabalho com a produção escrita, apontando que quando os alunos escrevem apenas para o professor, "a situação de emprego da língua é, pois, artificial. Afinal, qual a graça em escrever um texto que não será lido por ninguém ou que será lido apenas por uma pessoa (que por sinal corrigirá o texto e dará nota para ele)?” (GERALDI, 2006, p. 65).

O autor questionou o trabalho realizado com a produção de texto na escola, que apagava o aluno como autor, criando o que ele chama de "jogo da escola", motivado por uma escrita higienizada, seguidora de normas, mas sem projeto nem necessidade de dizer do educando. A esse processo ele denominou de redação escolar, entendendo que "na redação, não há um sujeito que diz, mas um aluno que devolve ao professor a palavra que lhe foi dita pela escola" (GERALDI, 2006, p. 128). E apresentou o seu contrário, uma produção escrita em que se perceba o aluno como um sujeito que tem o que dizer e para quem dizer por meio da produção de um texto. Essas reflexões estão amparadas em Bakhtin (2015) quando diz que "um traço essencial (constitutivo) do enunciado é o seu direcionamento a alguém, o seu endereçamento" (BAKHTIN, 2015, p. 301, grifos do autor).

Esses aspectos foram amplamente discutidos nos encontros de FC, procurando construir coletivamente a compreensão de que a produção textual pressupõe um projeto de dizer que só se materializa num texto/enunciado ${ }^{3}$ a partir de uma situação de interação real, em que o aluno/autor vislumbre o seu interlocutor. Desse modo, o que Geraldi (2006) definiu como "redação" não constituiria um processo de interlocução. Para o autor, "escrever é um gesto próprio, que implica necessariamente os sujeitos do discurso [...] 'exercício de redação' sempre foi pensado como um exercício, em que o sujeito só treinava” (GERALDI, 2006, p. 166).

\footnotetext{
${ }^{3}$ Considerando os conceitos bakhtinianos, o texto pode ser considerado como um enunciado, uma vez que organiza nosso projeto de dizer.
} 
Relacionamos a terminologia "redação escolar" utilizada por Geraldi (2006), ao que Costa-Hübes (2012, p. 10) define como "exercício de escrita":

A produção de texto como exercício de escrita são as atividades de produção textual em função do trabalho com determinado(s) conteúdo(s) da disciplina, objetivando ensinar o aluno a escrever. Por exemplo: introduzir ou concluir um texto, a partir de um fragmento dado; [...] Essas propostas de produção se esvaziam em si mesmas, já que uma vez atendido ao solicitado, o texto é avaliado (corrigido) pelo professor, encerrando-se aí o exercício de escrita.

A produção de texto como exercício de escrita encontra raízes em outras concepções de linguagem, em que a escrita é vista apenas como um sistema pronto, no qual regras devem ser assimiladas para se escrever bem, quase como um treino. $\mathrm{Ou}$, ainda, na escrita como expressão do pensamento, por meio da qual se compreende que os indivíduos devem transpor para o papel suas representações mentais, sem levar em conta o "outro", o processo de interação.

Para maior clareza da consolidação da proposta de produção textual sustentada na concepção interacionista e dialógica da linguagem, apresentamos os elementos que minimamente devem constar em um encaminhamento (comando) de produção escrita. Para isso, recorremos a Costa-Hübes (2012), que esquematizou a figura seguinte, amparada, por sua vez, em Geraldi (1991), quando discorre sobre as condições de produção: 


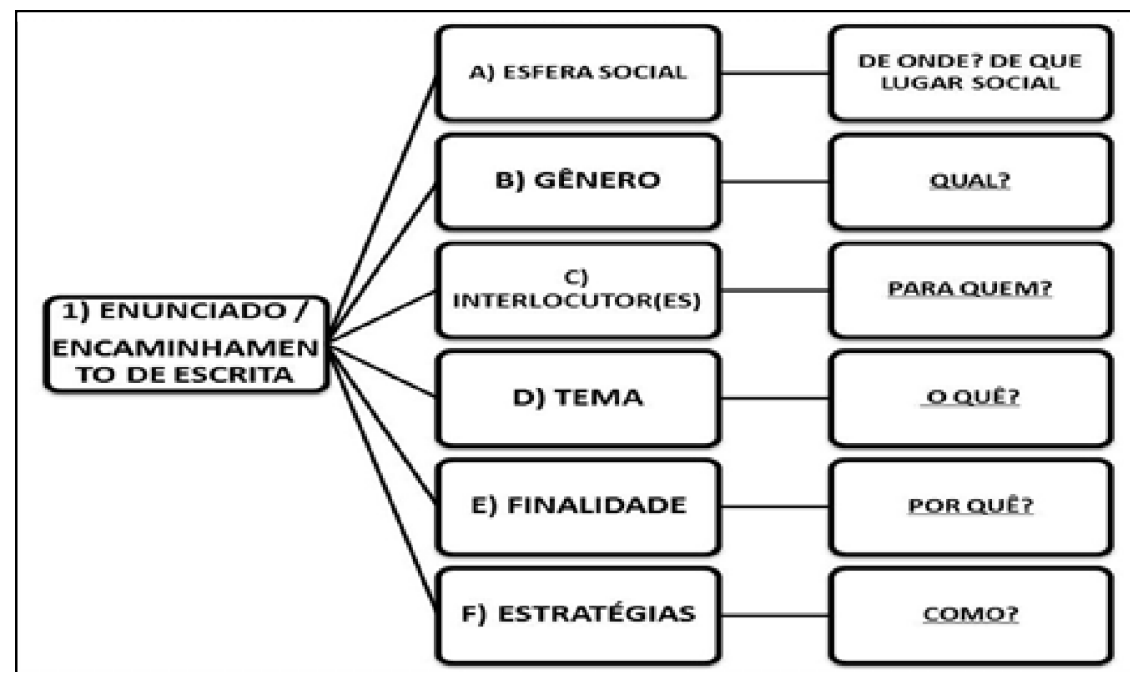

Fonte: Costa-Hübes (2012, p. 11).

Figura 1 - Elementos que encaminham uma proposta de produção de texto para a interação

Ao reforçar a importância de abranger tais elementos durante o encaminhamento da produção textual, Costa-Hübes (2012) está em consonância com as ideias bakhtinianas, pois, ao propor que contemplem a esfera social, os interlocutores, o gênero, o tema, a finalidade e as estratégias de produção, o próprio aluno-autor conseguirá ver a situação de interlocução que se apresenta, o que favorecerá a compreensão da escrita como forma de interação.

Nesse sentido, Geraldi (2010, p. 168) confirma:

A produção do texto exige articulações entre situação, relação entre interlocutores, temática, estilo do gênero e estilo próprio, o querer dizer do locutor, sua vinculações [...] Quer dizer, para além da superfície linguística do texto, há condições discursivas que orientam a materialização textual. 
Assim, produzir texto na escola, orientado pelo viés da interação, significa articular a linguagem com seus interlocutores, de modo que o discurso se estabeleça por meio do texto/enunciado em produção. Para que isso se concretize, é importante garantir, ao aluno, no encaminhamento da produção textual, clareza quanto aos seus propósitos discursivos. Essas questões foram amplamente discutidas com os participantes da FC, que procuraram analisar as propostas que vinham desenvolvendo em sala e as constantes em seus materiais didáticos, observando se continham ou não os elementos indicados na Figura 1.

\section{A Teoria e a Prática: reflexos na práxis em sala de aula}

Nos primeiros encontros de formação, enfatizamos a importância de compreender a produção de texto como um processo amplo que se organiza em várias etapas e envolve o encaminhamento da produção, a escrita do texto, a revisão e a reescrita. As reflexões iniciais se sustentaram em CostaHübes (2012), que estabelece uma diferenciação entre a produção de texto que nasce da necessidade de interação, de ter o que dizer para alguém, ou seja, uma escrita com vínculo social, dos meros exercícios de escrita com fins em si mesmos.

Após as primeiras discussões, solicitamos que os professores procurassem observar as atividades que estavam desenvolvendo durante a semana com a produção textual e que relatassem como organizaram o encaminhamento da produção que gerou o comando para a escrita do texto. E que, a partir daí, selecionassem um ou mais textos resultantes desse processo e trouxessem para o próximo encontro de formação.

Apresentamos, no quadro seguinte, o relato realizado por uma professora de $5^{\circ}$ ano e, na sequência, o analisamos a fim de perceber os reflexos do que foi discutido durante a formação. 


\section{Quadro 2 - Relato Reflexivo}

\begin{tabular}{|c|}
\hline $\begin{array}{l}\text { Relato de prática docente } \\
\text { A Escola Municipal, na primeira semana do mês de maio, organizou junto aos } \\
\text { professores, atividades para homenagear as mães no seu dia. Aproveitando o momento, a } \\
\text { professora apresentou alguns modelos de convite e explicou o que deve constar neste tipo de } \\
\text { texto. Logo após, solicitou aos alunos do } 5^{\circ} \text { ano, a confecção de um convite para o evento. O } \\
\text { aluno teria que produzir um texto convidando a mãe para prestigiar as apresentações } \\
\text { realizadas em sua homenagem no evento. Neste texto deveria constar também o dia, o horário } \\
\text { e o local do evento. Cada aluno, usando de sua criatividade, desenvolveu o texto do seu convite. } \\
\text { Alguns, antes de convidar a mãe, escreveram uma mensagem falando das qualidades dela. } \\
\text { Outros decoraram o convite desenhando coração, colando adereços, como flores, laços, ou } \\
\text { apenas elaborando o texto convidando a mãe. Enfim, cada aluno preparou de forma diferente } \\
\text { o seu convite, mas todos com o mesmo objetivo. }\end{array}$ \\
\hline $\begin{array}{l}\text { Encaminhamentos da Professora: } \\
\text { a. Gênero escolhido - Convite } \\
\text { b. Interlocutores - Mães } \\
\text { c. Tema - Dia das Mães } \\
\text { d. Finalidade - Convidar as mães para participar e prestigiar o evento. } \\
\text { e. Estratégias - Buscando uma situação real de interação, a professora: } \\
\text { - aproveitou o momento para encaminhar, simultaneamente, uma produção textual } \\
\text { - interativa e uma homenagem às mães pelo seu dia; } \\
\text { - apresentou alguns modelos de convite para apreciação da turma; } \\
\text { - explorou os suportes, oportunizando aos alunos a visualização de sua estrutura } \\
\text { - composicional, sem priorização; } \\
\text { - explicou o que deve constar neste tipo de texto; } \\
\text { solicitou aos alunos a confecção de um convite para o evento e sua entrega para as } \\
\text { mães, como finalização da atividade. }\end{array}$ \\
\hline
\end{tabular}

Fonte: Dados gerados na pesquisa

No relato apresentado sobre a forma de trabalho que precedeu a produção textual, podemos perceber que a docente compreendeu a importância de estabelecer uma necessidade real de interação, partindo de uma situação que estava sendo vivenciada na escola: a organização de uma homenagem por ocasião da passagem do Dia das Mães. E, nesse contexto, procurou desenvolver uma prática cotidiana de uso da escrita: o convite. 
Ao elaborar o comando de produção, a docente buscou seguir os elementos apontados por Costa-Hübes (2012), indicando a esfera social de onde escreveriam (escolar), o gênero a ser produzido (convite), o interlocutor (mãe), o tema (Dia das Mães), a finalidade (convidar para uma homenagem) e as estratégias para a escrita (que foram explicitadas no relato).

É importante destacarmos que, no momento em que apresentou oralmente o seu relato de prática, questionamos a professora se já era usual, em seu cotidiano escolar, observar todos esses elementos e a situação de interação quando trabalhava com a produção textual e obtivemos a explicação de que, pela primeira vez, tentara propor dessa maneira. Essa constatação já demonstra que as ações de FC, quando organizadas de modo a provocar reflexões que incidam sobre a prática, podem sim provocar mudanças.

Ressaltamos que, conforme o relato, a finalidade era convidar a mãe para uma homenagem na escola; contudo, alguns alunos, segundo relato da professora, "antes de convidar a mãe, escreveram uma mensagem falando das qualidades dela. Outros decoraram o convite desenhando coração, colando adereços, como flores, laços, ou apenas elaborando o texto convidando a mãe. Enfim, cada aluno preparou de forma diferente o seu convite". Esse trecho narrado pela docente demonstra que os educandos conseguiram perceber nessa atividade de produção uma necessidade real de interação, de modo que, tendo em vista o interlocutor (a mãe), assumiram-se como sujeito-autor que tem o que dizer e um estilo próprio para isso. Esse procedimento destaca a importância da escrita para a interação, conforme defende Costa-Hübes (2012, p. 10):

As práticas de produção de texto devem priorizar a interação com outro(s) interlocutor(es). Para isso, o ensino da língua escrita só irá acontecer quando conseguirmos mediar momentos de aprendizagem por meio dos quais o aluno possa 'mergulhar' em situações reais de interação. Em outras palavras: o aluno só aprenderá a escrever se vivenciar práticas cotidianas de uso da escrita.

Outro fator interessante assinalado pela docente refere-se ao procedimento adotado para apontar as estratégias de dizer dentro do gênero selecionado (convite). Nesse sentido, realizou uma sequência de atividades 
preparatórias para a produção textual que contemplaram: a) a situação real de interlocução "Buscando uma situação real de interação, a professora aproveitou o momento para encaminhar, simultaneamente, uma produção textual interativa e uma homenagem às mães pelo seu dia"; b) o reconhecimento do gênero a ser produzido: apresentou alguns modelos de convite para apreciação da turma; c) aspectos do estilo e construção composicional: explicou o que deve constar neste tipo de texto; d) a circulação do texto: entrega para as mães.

Em nossa análise, concluímos que a professora demonstrou compreensão do que foi abordado na formação e procurou articular o conhecimento teórico adquirido à prática em sala de aula. Contudo, ainda precisamos analisar como essa mudança da docente em relação ao modo de encaminhar uma proposta de escrita influenciou no desempenho discursivo nos textos de seus alunos. Como a professora nos disponibilizou três textos produzidos pelos educandos, resultantes do encaminhamento proposto, apresentamo-los na sequência, analisando-os a partir dos conceitos teóricos aqui já expostos.

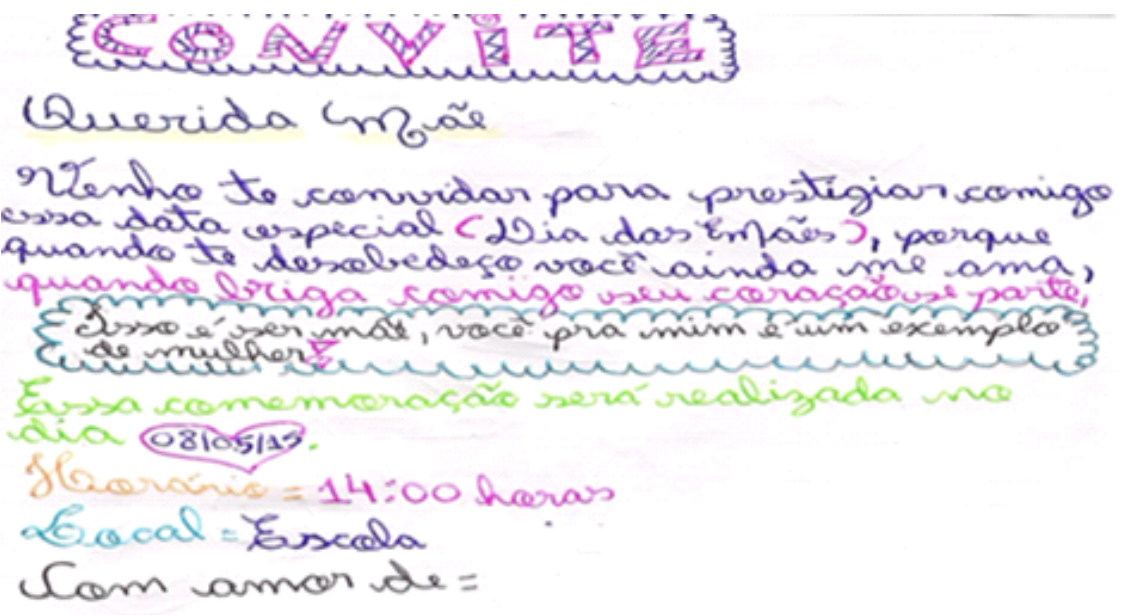

Fonte: Dados gerados na pesquisa.

Figura 2 - Texto 1, da aluna AS 
Podemos observar que o texto contempla os elementos básicos do gênero convite, pois traz o vocativo "Querida mãe", deixando bem marcado o interlocutor; apresenta a finalidade de sua produção, "convidar para comemorar o dia das mães"; o local; a data e a assinatura ${ }^{4}$. A aluna conseguiu marcar bem a presença de tais elementos, pois o próprio comando de produção trouxe orientações que apontavam para esse procedimento.

O principal elemento perceptível no texto é a necessidade de interação que ali está estabelecida: ao saber e conhecer quem seria seu interlocutor (a mãe), a criança produziu um texto/enunciado com uma necessidade de dizer algo, o que favoreceu o desenvolvimento do conteúdo, pois há muitas outras coisas ditas à mãe além do simples convite: "quando te desobedeço você ainda me ama, quando briga comigo seu coração parte. Isso é ser mãe, você pra mim é um exemplo de mulher!" Este trecho nos permite inferir a proximidade que há entre os interlocutores, já que se trata de um interlocutor real, conhecido, próximo do sujeito-autor. Todas essas informações são acrescidas ao convite pela necessidade que a filha tem em dizê-las à mãe, possibilitada pela escrita do texto do gênero. Assim, destacam-se, no texto, tanto o estilo do gênero como do próprio autor.

Também percebemos uma relação com outros discursos sociais, promovendo uma interdiscursividade/dialogicidade com o que está posto na sociedade sobre o amor materno: "você ainda me ama", "exemplo de amor".

Esse trabalho encaminhado pela docente e o texto que dele resultou corrobora o que postula as DCE, quando propõem o trabalho na escola com as práticas discursivas do cotidiano, presentes nos diversos gêneros:

É tarefa da escola possibilitar que seus alunos participem de diferentes práticas sociais que utilizem a leitura, a escrita e a oralidade, com a finalidade de inseri-los nas diversas esferas de interação. Se a escola desconsiderar esse papel, o sujeito ficará à margem dos novos letramentos. (PARANÁ, 2008, p. 48).

${ }^{4} \mathrm{O}$ local e assinatura constavam em todos os textos analisados, contudo, optamos por suprimir os nomes dos alunos autores e do local da homenagem, identificando-o apenas como escola. 
Assim, o ensino de LP deve considerar os aspectos sociais e históricos que incidem nas ações e interações dos sujeitos, com ênfase para o contexto de produção dos enunciados pelos quais o uso da língua se efetiva. Como o documento tem por base teórica as reflexões do Círculo de Bakhtin, destacam os tipos de "enunciados relativamente estáveis" como gêneros discursivos, reconhecendo que podem variar, assim como a língua, que não é estanque, fato que ocorreu no texto do aluno com os acréscimos feito ao convite. A proposta encaminhada pela professora apresenta-se coerente com o documento, pois propõe o trabalho na escola com as práticas discursivas do cotidiano, presentes nos diversos gêneros, conforme apregoa o documento:

O aprimoramento da competência lingüística do aluno acontecerá com maior propriedade se lhe for dado conhecer, nas práticas de leitura, escrita e oralidade, o caráter dinâmico dos gêneros discursivos. O trânsito pelas diferentes esferas de comunicação possibilitará ao educando uma inserção social mais produtiva no sentido de poder formular seu próprio discurso e interferir na sociedade em que está inserido. (PARANÁ, 2008, p. 53).

Acreditamos que, no encaminhamento com o gênero "convite", a professora conseguiu demonstrar esse caráter dinâmico de uso da linguagem, já que considerou o ensino da língua dentro de um propósito discursivo e atendendo a uma necessidade de interação.

Destacamos, a seguir, mais dois exemplos de textos produzidos, resultados do encaminhamento apresentado pela professora participante do processo de FC. 


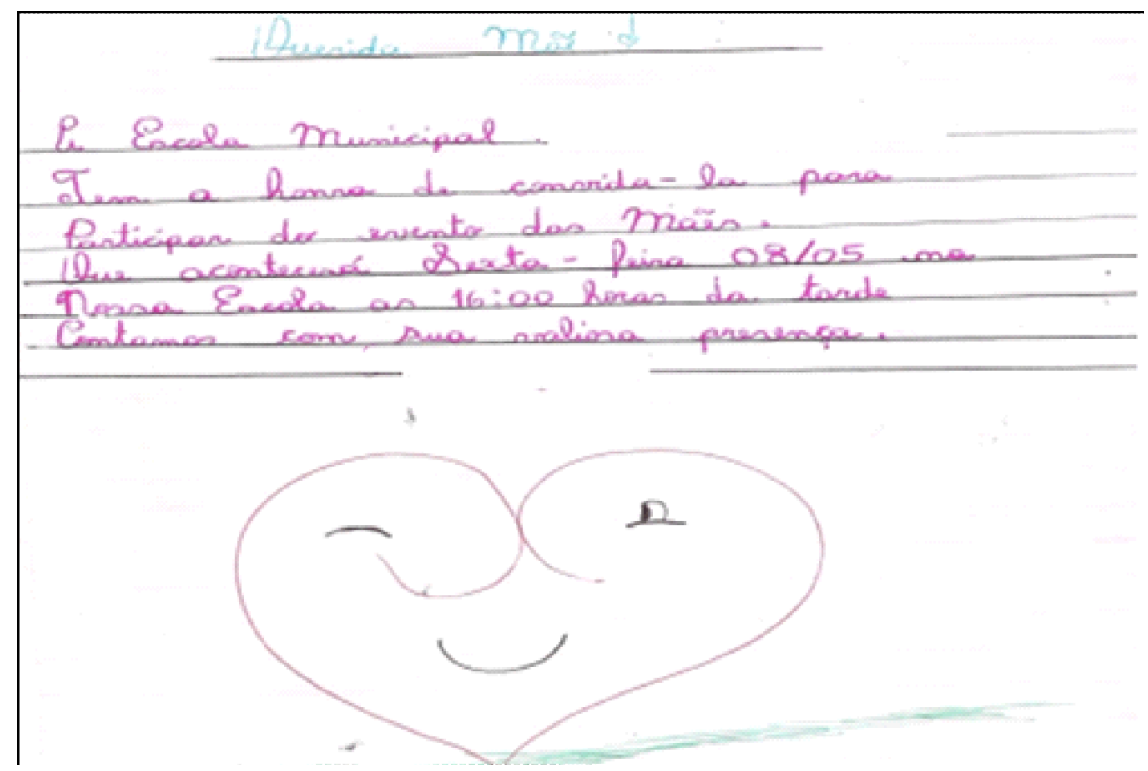

Fonte: Dados gerados na pesquisa

Figura 3: Texto 2, da aluna AJ

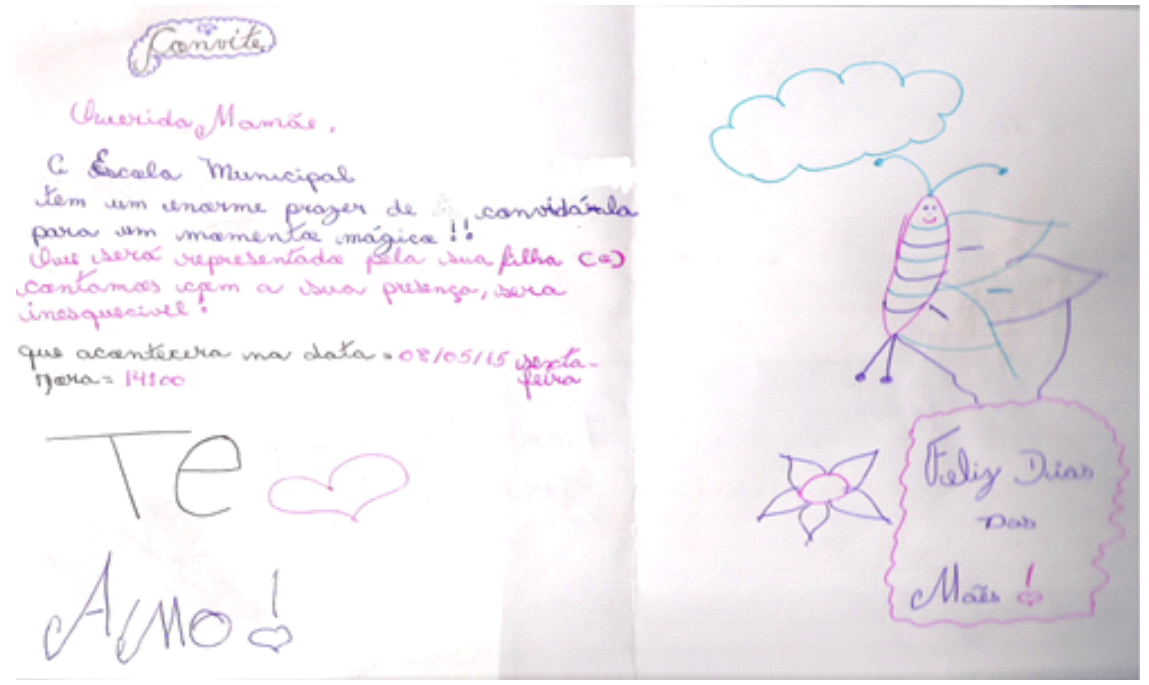

Fonte: Dados gerados na pesquisa

Figura 4: Texto 3, da aluna AN 
Ao analisar as escolhas linguísticas nos Textos 2 e 3 , percebemos a presença de expressões que reportam a outros textos do gênero convite, como: "Tem a honra de convidá-la", "contamos com a sua valiosa presença", "Será inesquecível". Essas ocorrências nos levam a inferir que tais expressões estivessem presentes nos convites trabalhados durante a leitura pela professora, visando ao reconhecimento do gênero. Um fator presente nesses dois textos que difere do texto 1 é o fato de terem escrito o convite em nome da escola (esfera escolar) - Texto 3: "a Escola Municipal tem o prazer de convidá-la"; Texto 2: "Tem a honra de convidá-la" -, enquanto que, no Texto 1, percebemos que a própria criança é que realiza o convite. Esse fato nos leva a crer que temos mais nítida, nos Textos 2 e 3, a influência dos textos de apoio, pois registraram com maior ênfase as marcas linguísticas do estilo do gênero e da construção composicional, além de empregarem coerentemente os elementos constitutivos do gênero (vocativo, data, local e horário). Esses dois alunos seguiram a estrutura básica dos textos enviados pela própria escola, utilizando a terceira pessoa "que será representado pela sua filha(o)", e (no Texto 3) até mesmo o que costuma ser recorrente nos convites escolares: a marca indicativa de gênero "filha(o)", assumindo a escola como o locutor para a mãe.

Contudo, o Texto 3 traz, ao final do convite, a filha assumindo-se como interlocutora, ao escrever com letras maiores do que no corpo do convite, "Te amo"; nesse momento temos uma necessidade pessoal da filha em interagir com a mãe; por isso, ela se coloca como sujeito do que diz e assume a palavra, acrescentando uma informação, conforme ocorreu no Texto 1. Salientamos, também, que os desenhos presentes nos três convites constituem marcas da linguagem não verbal, formas pessoais de expressar, além do ato de convidar. Os sentimentos que nutrem pela mãe (a interlocutora) tornam-se parte integrante do processo interlocutivo.

Mesmo que, em alguns momentos os textos tenham demonstrado o discurso já pronto nos convites com os quais tenham tido contato prévio, todos se sustentaram em uma interação real com a mãe, em maior ou menor grau de interatividade, o que comprova que o fato de ter determinado o interlocutor de um texto, com a certeza de que está produzindo para alguém que irá ler, favorece o projeto de dizer, a adequação da linguagem e dos elementos do próprio gênero, conforme sua finalidade comunicativa. Assim, 
Reconhecer os gêneros como formas de dizer sócio-historicamente construídas e elegê-los como objeto de ensino, pelo fato de incluir aspectos da enunciação e do discurso, indubitavelmente, pode contemplar, de forma mais satisfatória, o processo de produção e de compreensão de textos. (COSTA-HÜBES, 2008, p. 154).

Essa análise nos sugere que o modo como o professor encaminha o trabalho de produção textual é de suma importância, pois permite ao aluno ver "sentido" no que é produzido, ou seja, compreender a escrita como forma de interação entre um eu e o outro.

\section{Considerações Finais}

A análise e reflexões apresentadas neste texto corroboram a defesa de que a FC, mesmo que não possa dar conta de resolver os inúmeros problemas de ensino, pode contribuir muito com o trabalho pedagógico na sala de aula, uma vez que instaura maior compreensão sobre a base teórica que dá sustentação ao ensino de LP.

Foi com esse propósito que este texto foi construído: com o intuito de apontar caminhos para se romper com a mecanização da escrita na escola e demonstrar que a FC ainda é uma opção válida para articular a teoria e a prática, fato que acreditamos termos demonstrado ao analisar a prática de uma professora participante do processo de formação. Segundo Magalhães (2004, p. 79), “a compreensão das práticas de sala de aula pode levar o agente a uma intervenção produtiva no contexto escolar, na reconstrução das práticas didáticas e na relação da escola com a sociedade mais ampla”.

Durante a realização dos encontros de formação, nos relatos dos docentes sobre as práticas que desenvolvem em salas de aula, pudemos perceber que existem tentativas para desenvolver um trabalho que considere a língua numa perspectiva dialógica, discursiva, conforme o previsto nos documentos oficiais. Mas grande parte das dificuldades em se atingir um trabalho consistente nesta concepção de linguagem decorre da falta de uma política de FC mais expressiva, que permita um estudo contínuo que possibilite um olhar para a própria prática à luz dos conceitos teóricos norteadores do ensino. 


\section{Referências}

BAKHTIN/VOLOCHINOV. Marxismo e filosofia da linguagem. São Paulo: Hucitec, 2014 [1929].

BAKHTIN, M. Problemas da poética de Dostoiéviski. Tradução: Paulo Bezerra. 5.ed. Rio de Janeiro: Forense Universitária, 2010 [1929].

BAKHTIN, M. Estética da criação verbal. São Paulo: Martins Fontes, 2015 [1979].

BRASIL. Secretaria de Educação Fundamental. Parâmetros curriculares nacionais. língua portuguesa. Brasília: MEC/SEF, 1997.

BRASIL. Secretaria de Educação Fundamental. Parâmetros curriculares nacionais: língua portuguesa. Brasília: MEC/SEF, 1998.

BRONCKART, J. P. Atividade de linguagem, textos e discursos: por um interacionismo sócio-discursivo. Tradução Anna Rachel Machado. São Paulo: Educ, 1999.

COELHO, G. M. de S. Formação contínua e pesquisa colaborativa: impulsionando transformações em contextos escolares. Revista Marcas Educativas, Teresina, v. 1, n. 1, p. 70-82, ago. 2011.

COSTA-HÜBES, T. C. O processo de formação continuada dos professores do oeste do Paraná. Um resgate histórico-reflexivo da formação em Língua Portuguesa. 2008. Tese (Doutorado em Estudos da Linguagem) Universidade Estadual de Londrina, Londrina.

COSTA-HÜBES, T. C. Reflexões sobre os encaminhamentos de produção textual: enunciados em diálogo com outros enunciados. In: ENCONTRO DO CELSUL, 10., 2012, Cascavel. Anais... Cascavel: UNIOESTE, 2012. p. 1-15.

COSTA-HÜBES, T. C.; GEDOZ, S. Articulações entre currículo e formação continuada: desafios do processo de ensino. In: APARÍCIO, A. S.; SILVA, S. R. (Org.). Ensino de lingua materna e formação docente: teoria, didática e prática. Campinas SP, Pontes Editores, 2013. p. 215-239. 
CRISTOVÃO, V. L. L. A relação entre teoria e prática no desenvolvimento do professor. In: MAGALHÃES, M. C. C. (Org.). A formação do professor como um profissional crítico: linguagem e reflexão.

Campinas: Mercado das Letras, 2004. p. 251-278.

FARACO, C. A. Linguagem \& Diálogo: as ideias linguísticas do Círculo de Bakhtin. São Paulo: Parábola, 2013.

GASPAROTTO, D. M.; MENEGASSI, R. J. Modos de participação do professor na reescrita de alunos: enfoque na análise linguística. In: ENCONTRO DO CELSUL, 10., 2012, Cascavel. Anais... Cascavel: UNIOESTE, 2012. p. 1-15.

GERALDI, J. W. Portos de passagem. São Paulo: Martins Fontes, 1991. GERALDI, J. W. (Org.). O texto na sala de aula. São Paulo: Ática, 2006 [1984].

GERALDI, J. W. A aula como acontecimento. São Carlos: Pedro \& João, 2010.

MAGALHÃES, M. C. C. A linguagem na formação de professores reflexivos e críticos. In: MAGALHÃES, M. C. C. (Org). A formação do professor como um profissional crítico: linguagem e reflexão. Campinas: Mercado das Letras, 2004. p. 59-117.

PARANÁ. Secretaria de Estado da Educação. Superintendência de Educação. Departamento de Ensino de Primeiro Grau. Currículo Básico para a Escola Pública do Estado do Paraná. Curitiba: SEED, 1990.

PARANÁ. Secretaria de Estado da Educação. Diretrizes Curriculares Estaduais de Lingua Portuguesa. Curitiba: SEED, 2008.

PIMENTA, S. G. Pesquisa-ação crítico-colaborativa: construindo seu significado a partir de experiências com a formação docente. Educação e Pesquisa, São Paulo, v. 31, n. 3, p. 521-539, 2005.

Recebido em: 31/08/2015

Aceito: $20 / 02 / 2016$ 